\title{
Influence of $30 \%$ Hydrogen Peroxide Bleaching on Compomers in their Surface Modifications and Thermal Expansion
}

\author{
Choong-Bo JUNG, Hyung-Il KIM, Kyo-Han KIM ${ }^{1}$ \\ and Yong Hoon KWON ${ }^{1}$ \\ Department of Dental Materials, College of Dentistry, \\ Pusan National University, Pusan 602-739, Korea \\ ${ }^{1}$ Department of Dental Biomaterials, \\ College of Dentistry, Kyungpook National University, \\ Taegu 700-422, Korea
}

Received July 15, 2002/Accepted September 30, 2002

\begin{abstract}
The surface modifications and the coefficient of thermal expansion of compomers after treatment with a $30 \%$ hydrogen peroxide bleaching agent were investigated. Three compomers (Compoglass F, Elan and F2000) were nonbleached and bleached for 1 and 3 days. The surface modification and the coefficient of thermal expansion of each bleached compomer were evaluated using a scanning electron microscope and a thermomechanical analyzer, respectively. As a result, Compoglass F and Elan showed slight surface degradation, whereas F2000 showed many cracks on its surface and these cracks were not observed in Compoglass $F$ and Elan. Bleached Elan and F2000 has changed to the extent where their the coefficient of thermal expansion increased compared with those of nonbleached specimens. In addition, bleached compomers showed a strong inverse correlation between the coefficient of thermal expansion and the volume percent of filler.
\end{abstract}

Key words : 30\% hydrogen peroxide, Scanning electron microscope, Thermal expansion

\section{INTRODUCTION}

The use of a bleaching agent for whitening intrinsically and extrinsically stained teeth has became routine in the esthetic or conservative dental treatment. The cause of dental discoloration has two different sources of stains according to the location and reasons for the stains. Extrinsic discoloration occurs due to the deposition of stained materials onto the tooth surface. On the other hand, intrinsic discoloration occurs due to the presence of chromogenic materials within the tooth ${ }^{1)}$. Although the exact bleaching mechanism on the tooth is not fully known, degradation of high molecular weight through oxidation was suggested as the bleaching mechanism of organic molecules. A variety of whitening methods, including vital bleaching, direct composite resin veneers, porcelain veneers and ceramic crowns, have been developed and used over the years with hydrogen peroxide and carbamide peroxide in varying concentrations. The bleaching agent treatment may be performed either in the dental clinic through the use of $30 \sim 35 \%$ hydrogen peroxide and the direct monitoring of the dentist, or at home with low concentration home bleaching commercial products. In general, the later is performed through the use of $10 \sim 22 \%$ carbamide peroxide in the 
form of mouthguards. Numerous studies have examined the effects of bleaching agents on dental restorative materials and teeth with regard to color, hardness, dissolution and morphological changes ${ }^{2-9)}$. In many cases, the reported results did not converge to draw one clear conclusion from research groups, even though similar bleaching agents had been used.

Recently introduced polyacid-modified composite resins ("compomers") are of increasing clinical interest as a result of good esthetics, moderate fluoride release, easy handling properties and improved physical properties ${ }^{10-12)}$. Compomers are basically composed of fluoroalumino-silicate-glass, one of the main ingredients of glass ionomer cement, polycarboxyl acid and monomers ${ }^{13)}$. Usually, compomers are reinforced with barium, strontium or ytterbium. A minute amount of a photosensitizer, camphorquinone, is also included in a compomer to initiate photopolymerization after the absorption of incoming curing light. In terms of composition, compomer is basically composite resin. The release of fluoride from fluoride releasing compomers in various storage media was of major interest to researchers ${ }^{14-16)}$. However, valuable information on surface modification and thermal expansion properties after bleaching was rare. Furthermore, in a situation that the compomer-filled-teeth interact with a bleaching agent during the dental bleaching treatment and surface modification after fluoride release, it is necessary to clarify what characters of compomers are affected during the bleaching process.

The purpose of this study was to investigate the surface modifications in addition to the coefficients of thermal expansion of compomers after treatment with bleaching agent, $30 \%$ hydrogen peroxide, and to test the correlation between the volume percent of filler and the coefficient of thermal expansion of compomers.

\section{MATERIALS AND METHODS}

For the observation of surface modifications caused by the treatment of $30 \%$ hydrogen peroxide (Sigma Chemical Co., St. Louis, USA) in compomers, a scanning electron microscope (S-4200, Hitachi, Tokyo, Japan) was used. Each compomer in Table 1 was poured into a round Teflon mold ( $5 \mathrm{~mm}$ in diameter and $2.5 \mathrm{~mm}$ in depth) and covered with a transparent slide glass. Each sample was photopolymerized for 40 seconds with $700 \mathrm{~mW} / \mathrm{cm}^{2}$ light intensity (CuringLight XL 3000, 3M, St. Louis, USA). After the light curing, the covered glass was carefully removed. The specimens were ground roughly using several different $\mathrm{SiC}$ papers and then ground ultra-finely using diamond compound pastes. They were then allowed to stand in air for one day. The

Table 1 List of compomers tested in the experiments

\begin{tabular}{llcc}
\multicolumn{1}{c}{ Compomer } & \multicolumn{1}{c}{ Manufacturer } & Shade & Batch\# \\
\hline Compoglass F & Vivadent, Schaan, Liechtenstein & A3 & 902643 \\
Elan & Kerr, Orange, USA & A3 & 810257 \\
F2000 & 3M, St.Paul, USA & A3 & 19990219 \\
\hline
\end{tabular}


ground specimens were immersed into a bleaching agent for 1 and 3 days. The nonbleached specimens were used as controls.

The coefficients of thermal expansion of three commercially available light-curing compomers (Table 1) that had been nonbleached and bleached for 1 and 3 days were evaluated. Samples $(1.5 \mathrm{~mm} \times 2 \mathrm{~mm} \times 13 \mathrm{~mm})$ were prepared in a metal die. The same light curing machine and photopolymerization condition (40-second exposure time and $700 \mathrm{~mW} / \mathrm{cm}^{2}$ light intensity) taken in the scanning electron microscope study were used to polymerize compomers. Since the size of the light guide (radius $=3.5 \mathrm{~mm}$ ) was not large enough to cover the size of the metal die at one time, the light guide was moved to the next position after finishing the light curing at one place. After finishing the polymerization on one side, the sample was removed from the metal die and the other side of the sample was light cured again for 40 seconds in order to assure a higher degree of polymerization. Five specimens were prepared for each compomer. All light-cured specimens for the linear thermal expansion experiment were immersed in the bleaching agent for 1 and 3 days except for the control specimens.

A thermomechanical analyzer (TMA) (TMA 1000, Rheometric Scientific Inc., Piscataway, USA) was used to measure the liner thermal expansion in the nonbleached and bleached compomers for 1 and 3 days. Displacement of the probe due to the sample expansion was recorded in the temperature range $20 \sim 80^{\circ} \mathrm{C}$. The heating rate of the machine was set at $5{ }^{\circ} \mathrm{C} / \mathrm{min}$ to attain a stable heating in the sample. Measurement was performed only once on each sample and after each measurement, the machine was cooled down to below $20^{\circ} \mathrm{C}$. The coefficient of thermal expansion was calculated from the displacement by dividing with the temperature. The data were analyzed by one-way ANOVA followed by Duncan's multiple range test for variables among groups at the 0.05 level of significance.

\section{RESULTS}

Table 2 shows the filler content (vol\%) and the coefficients of thermal expansion $\left(\mu \mathrm{m} /{ }^{\circ} \mathrm{C}\right)$ in the temperature range $20 \sim 80^{\circ} \mathrm{C}$ for each compomer that was nonbleached and bleached for 1 and 3 days. The filler content and the coefficient of thermal ex-

Table 2 The filler content $(\operatorname{vol} \%)$ and the coefficient of thermal expansion $\left(\mu \mathrm{m} /{ }^{\circ} \mathrm{C}\right)$ in the temperature range of $20-80{ }^{\circ} \mathrm{C}$ for each compomer nonbleached and bleached for 1 and 3 days

\begin{tabular}{lcccc}
\hline \multirow{2}{*}{ Compomer } & \multirow{2}{*}{$\begin{array}{c}\text { Filler } \\
\text { Content }(\text { vol\% })\end{array}$} & \multicolumn{2}{c}{ Coefficient of thermal expansion $\left(\mu \mathrm{m} /{ }^{\circ} \mathrm{C}\right)$} \\
\cline { 3 - 5 } & 56 & Non-bleached & Bleached-1 day & Bleached-3 days \\
\hline Compoglass $\mathrm{F}$ & 58 & $54.27 \pm 0.72$ & $56.74 \pm 0.58$ & $50.92 \pm 1.42$ \\
Elan & 63 & $41.14 \pm 0.80$ & $47.55 \pm 0.94$ & $47.67 \pm 0.90$ \\
F2000 & $24.38 \pm 0.97$ & $33.05 \pm 0.47$ & $34.41 \pm 0.67$ \\
\hline
\end{tabular}

The volume percent of the filler was calculated from the relation between volume percent and weight percent in each compomer. The weight percent of each compomer was informed by the manufacturers. 
pansion of each compomer were found to differ with statistical significance $(p<0.01)$ after different periods of bleaching. Elan and F2000 showed marked change in the coefficient of thermal expansion on the first day of bleaching.

Fig. 1 shows the morphology of Compoglass F. As shown, Compoglass F was mainly composed of $1-\mu \mathrm{m}$-size filler. Among fillers of this size, smaller fillers at the size of $0.2 \sim 0.5 \mu \mathrm{m}$ were also observed. The surfaces appeared to gradually decompose such that the discernible filler-matrix boundary became less clear. Fig. 2 shows the morphology of Elan. Elan was composed of irregularly shaped fillers at the size of $1 \sim 3 \mu \mathrm{m}$. Some of its fillers looked like "Swiss-cheese" after bleaching due to its apparent porous surface. This kind of filler was also observed in Compoglass F. Fig. 3 shows the morphology of F2000. As shown, F2000 showed the largest filler

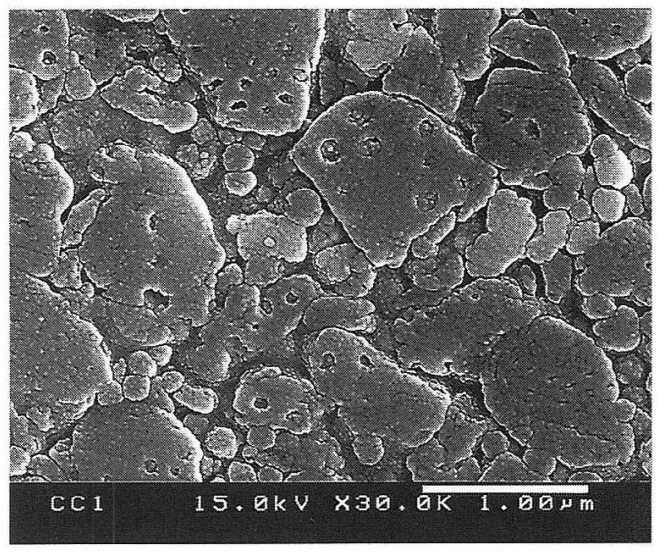

(a)

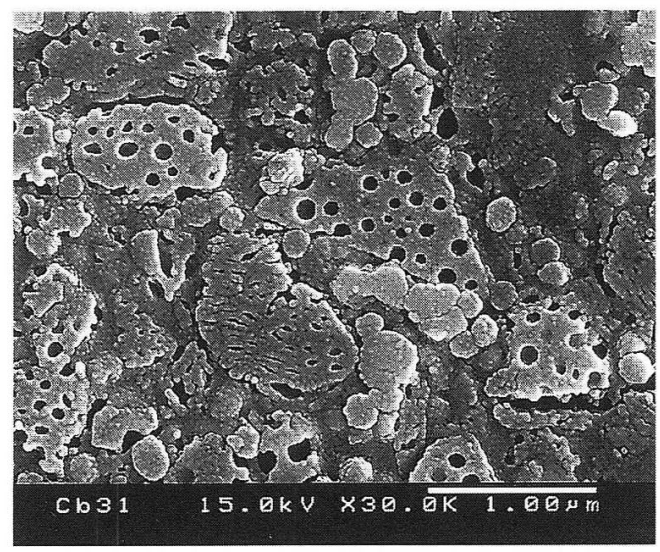

(b)

Fig.1 Scanning electron micrographs of Compoglass F treated with $30 \%$ hydrogen peroxide for (a) 0 (nonbleached) and (b) 3 days.

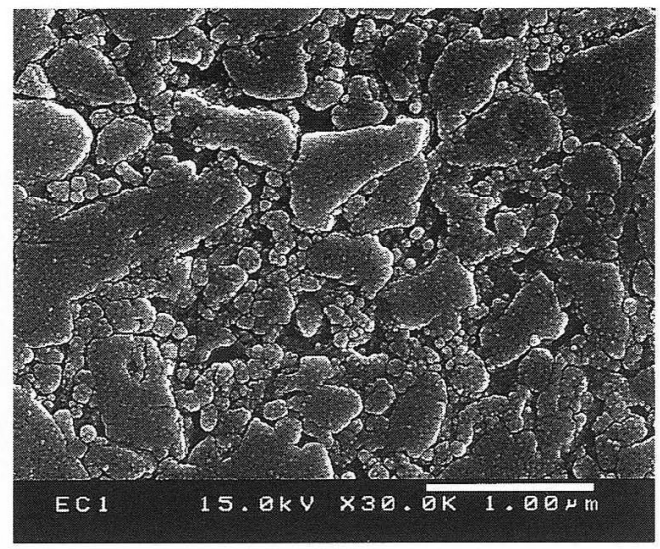

(a)

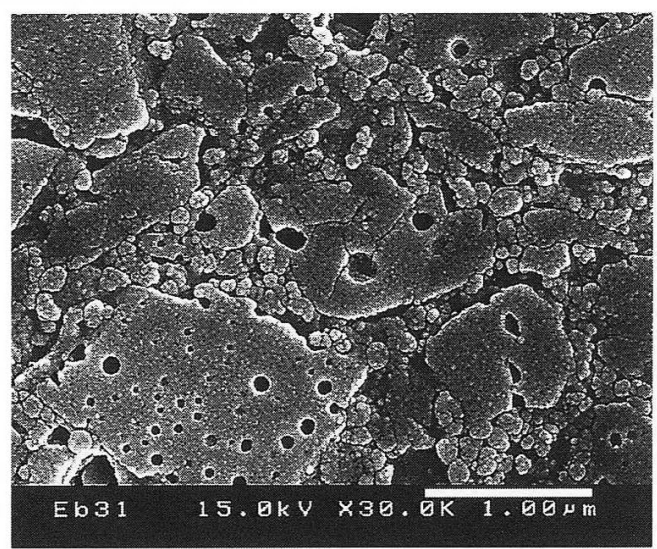

(b)

Fig. 2 Scanning electron micrographs of Elan treated with 30\% hydrogen peroxide for (a) 0 (nonbleached) and (b) 3 days. 


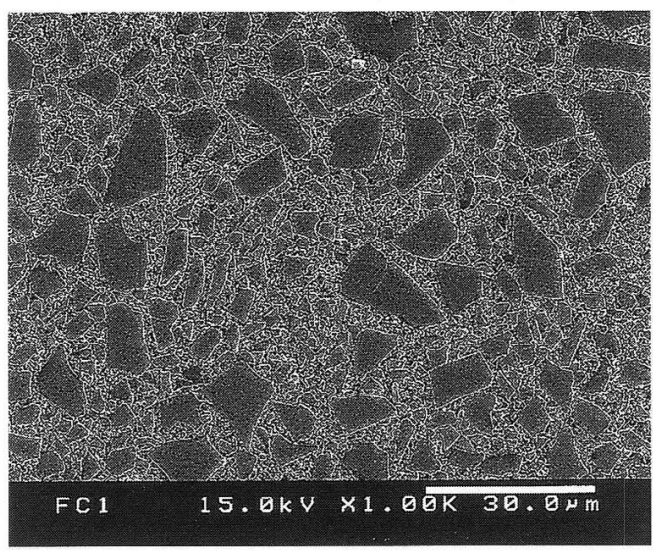

(a)

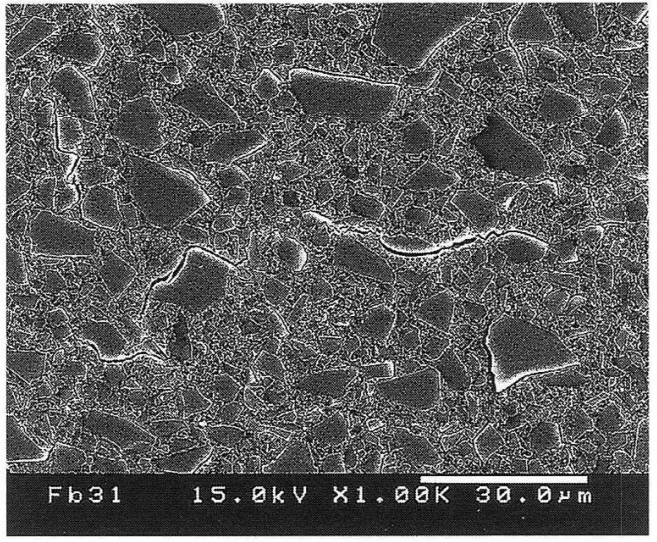

(b)

Fig. 3 Scanning electron micrographs of F2000 treated with $30 \%$ hydrogen peroxide for (a) 0 (non-bleached) and (b) 3 days.

size, approximately $3 \sim 10 \mu \mathrm{m}$, among the investigated compomers. Several fillers showed an apparent detachment at the filler-matrix interfaces. Cracks originating from the filler-matrix interfaces were generally propagated along the lateral side of the filler and the width of each crevice was increased as the number of days in bleaching agent was increased. Fig. 4 shows the relation between the volume percent of filler and the coefficient of thermal expansion for different periods of the bleaching process. An inverse linear relation was shown and the correlation coefficient changed slightly from -0.98 to -0.99 as the length of time in the bleaching agent increased from 0 (non-bleached) to 3 days. The slope of each straight line declined as the length of time in the bleaching agent increased. 


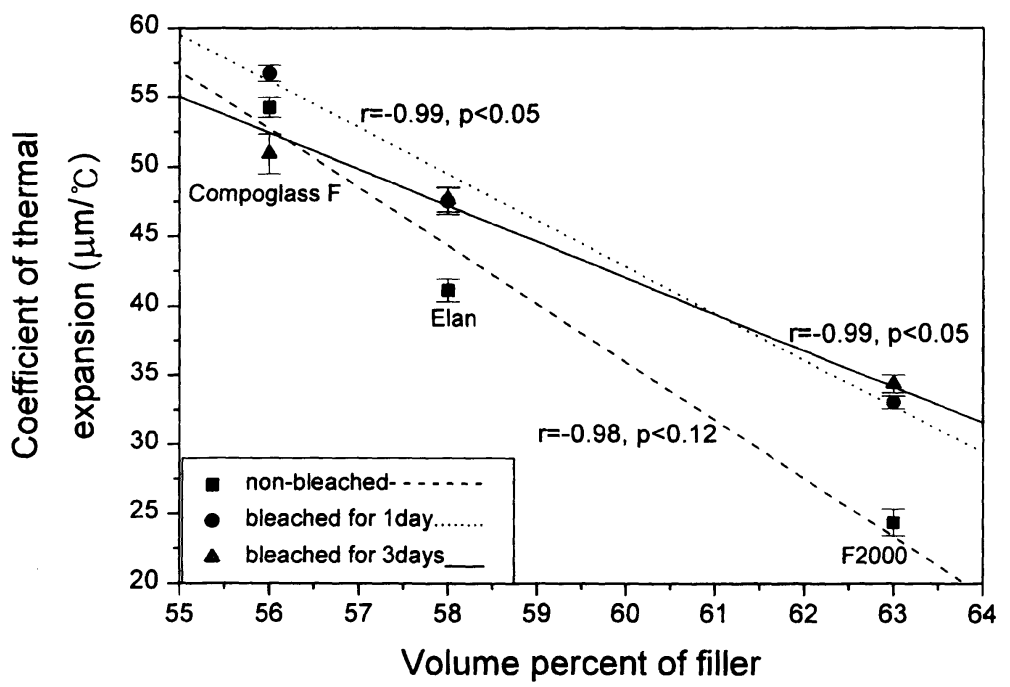

Fig. 4 The relation between the volume percent of filler and the coefficient of thermal expansion in the compomers for different periods of bleaching.

\section{DISCUSSION}

The effectiveness of hydrogen peroxide $\left(\mathrm{H}_{2} \mathrm{O}_{2}\right)$ is enhanced by the presence of organic and inorganic materials which accelerate the decomposition of hydrogen peroxide to hydroxyl radical intermediates, which in turn eventually combine to form oxygen and water ${ }^{17)}$. Compomers that were immersed in a bleaching agent absorb the decomposed water by osmotic pressure and in this case, the absorption rate between the filler and the matrix were different. In the oral milieu, the difference in the expansion between the filler and the matrix due to the absorption of water may initiate crack formation in the filler-matrix interface or may cause previously formed $\operatorname{crack}(\mathrm{s})$ to lengthen. In brittle materials such as dental composites or porcelain, the existence of (micro)cracks on the surface or inside the material decrease the strength of material ${ }^{18,19)}$. Once a crack has formed on the surface, stress and strain will cause the crack tip to extend once a critical value of the material is exceeded. At low filler content, the crack extends almost linearly. By increasing the filler content, the number of generated microcracks increased and their distribution also widened. Generated microcracks became main cracks by deflection from one direction to another direction and by coalescence with distributed microcracks ${ }^{20,21}$. The main crack typically propagates by taking a simple route to advance. In the case of F2000, the crack propagated in a complicated manner due to the higher filler content and random distribution of the fillers; it generally spread along the long lateral side of the filler. If two different cracks meet at the corner of the filler, they would combine and spread further by following the outgoing direction of the larger crack. Extensive 
cracking and roughening caused by the bleaching agent were also observed on the surface of composite resins ${ }^{22,23)}$. However, crack generation was not a general condition in every composite resin as it was in the compomers, and for this reason, it is not clear whether the formed crack affects the coefficient of thermal expansion.

The most apparent morphological difference between F2000 and Elan or Compoglass $\mathrm{F}$ was in the exposed microcavities and micropores in the filler or the matrix. Between Compoglass F and Elan, Compoglass F showed more apparent and abundant micropores and microcavities on the surface.

Previously, a strong inverse correlation between the filler content and the coefficient of thermal expansion in the dental composites was reported ${ }^{24-28)}$. In the compomers used in the present experiment, the same strong inverse correlation $(\mathrm{r}<$ -0.98 ) between the filler content and the coefficient of thermal expansion was found. The same tendency in the composite resins and compomers is attributed to the fact that the compositions of compomers are basically close to the composite resins. For this reason, it is natural to have the same inverse correlation both in the composite resins and compomers.

The clinical implications of the present findings that the bleaching process generally makes the compomers expand more readily during the bleaching, but it remains unclear whether this works positively or negatively in circumstances where there is no available data regarding the coefficient of thermal expansion of the bleached tooth. The daily oral environment is very complicated in terms of thermal stimuli. To know the effect of a bleaching agent on dental materials and teeth in a complicated thermal environment, controlled studies would be particularly valuable to enhance understanding of these effects in the tooth-restorative materials interactions.

\section{ACKNOWLEDGEMENT}

The authors thank Dr. Sang-Geul Lee and Ki-Ju Hwang of the Korea Basic Science Institute, Taegu Branch, Korea, for their assistance in using SEM and TMA.

\section{REFERENCES}

1) Nathoo, S. A.: The chemistry and mechanism of extrinsic and intrinsic discoloration, $J$ Am Dent Assoc $128: 6 \mathrm{~s}-10 \mathrm{~s}, 1997$.

2) Bitter, N.C.: A scanning electron microscopy of the effect of bleaching agents on enamel: A preliminary report, J Prosthet Dent 67:852-855, 1992.

3) Ernst, C. P., Marroquin, B. B. and Willershausen-Zönchen, B.: Effects of hydrogen peroxide containing bleaching agents on the morphology of human enamel, Quint Int $27: 53-53$, 1996.

4) Fay, R. M., Servos, T. and Powers, J. M.: Color of restorative materials after staining and bleaching, Oper Dent $24: 292-296,1999$.

5) Hummert, T. W., Osborne, J. W., Norling, B. K. and Cardenas, H. L.: Mercury in solution following exposure of various amalgams to carbamide peroxides, Am J Dent 6 : 305-309, 1993.

6) Lewinstein, I., Hirschfeld, Z., Stabholz, A. and Rotstein, I.: Effect of hydrogen peroxide and sodium perborate on the microhardness of human enamel and dentine, $J$ Endodont 
$20: 61-63,1994$.

7) Monaghan, P., Trowbridge, T. and Lautenschlager, E.: Composite resin color change after vital tooth bleaching, J Prosthet Dent 67 : 778-781, 1992.

8) Peutzfeldt, A., Garcia-Godoy, F. and Asmussen, E.: Surface hardness and wear of glass ionomers and compomers, Am J Dent $10: 15-17,1997$.

9) Rosentiel, S. F., Gegauff, A. G., McCafferty, R. J. and Johnston, W. M.: In vitro tooth color change with repeated bleaching, Quint Int 22:7-12, 1991.

10) Attin, T., Vataschki, M. and Hellwig, E.: Properties of resin-modified glass ionomer restorative materials and two polyacid-modified resin composite materials, Quint Int 27 : 203-209, 1996.

11) Peters, T.C., Roeters, J. J. and Frankenmolen, F. W.: Clinical evaluation of Dyract in primary molars: 1-year results, Am $J$ Dent $9: 83-88,1996$.

12) Suljak, J. P. and Hatibovic-Kofman, S.: A fluoride release-adsorption-release system applied to fluoride-releasing restorative materials, Quint Int $27: 635-638,1996$.

13) Mclean, J. W., Nicholson, J.W. and Wilson, A. D.: Proposed nomenclature for glassionomer dental cement and related materials, Quint Int 25 :587-589, 1994.

14) Attin, T., Buchalla, W., Siewert, C. and Hellwig, E.: Fluoride release/uptake of polyacid-modified resin composites (compomers) in neutral and acidic buffer solutions, J Oral Rehabil 26 : 388-393, 1999.

15) Geurtsen, W., Leyhausen, G. and Garcia-Godoy, F.: Effect of storage media on the fluoride release and surface microhardness of four polyacid-modified composite resins (compomers), Dent Mater $15: 196-201,1999$.

16) Robertello, F. J., Meares, W. A., Gunsolley, J. C. and Baughan, L. W.: Effect of peroxide bleaches on fluoride release of dental materials, Am J Dent 10:264-267, 1997.

17) Carlsson J.: Salivary peroxidase: an important part of our defense against oxygen toxicity, J Oral Pathol 16 : 412-416, 1987.

18) Kim, K. H., Park, J. H., Imai, Y. and Kishi, T.: Fracture toughness and acoustic emission behavior of dental composite resins, Eng Fracture Mechan 40:811-819, 1991.

19) Kim, K. H., Park, J.H., Imai, Y. and Kishi, T.: Microfracture mechanism of dental resin composites containing spherically-shaped filler particles, J Dent Res 73:499-504, 1994.

20) Faber, K. T. and Evans, A. G.: Crack deflection processes, Acta Metall 31:565-576, 1983.

21) Pessotti, G., Tanaka, I. and Okamoto, T.: Si3N4/SiC whisker composite without sintering aids, J Am Ceram Soc 73 : 3039-3045, 1990.

22) Bailey, S.J. and Swift, E. J.: Effect of home bleaching products on composite resins, Quint. Int 23 : 489-494, 1992.

23) Cullen, D. R., Nelson, J.A. and Sandrik, J. L.: Peroxide bleaches effect on tensile strength of composite resins, J Prosthet Dent 69 : 247-249, 1993.

24) Hashinger, D. T. and Fairhurst, C. W.: Thermal expansion and filler content of composite resins, J Prosthet Dent $52: 506-510,1984$.

25) Powers, J. M., Hostetler, R. W. and Dennison, J. B.: Thermal expansion of composite resins and sealants, $J$ Dent Res $58: 584-587,1979$.

26) Söerholm, K. J. M.: Influence of silane treatment and filler fraction on thermal expansion of composite resins, J Dent Res 63 : 1321-1326, 1984.

27) Versluis, A., Douglas, W. H. and Sakaguchi, R. L.: Thermal expansion coefficient of dental composites measured with stain gauges, Dent Mater 12 : 290-294, 1996.

28) Yamaguchi, R., Powers, J. M. and Dennison, J. B.: Thermal expansion of visible-lightcured composite resins, Oper Dent 14:64-67, 1989. 